\title{
Earthquake forecasts for the CSEP Japan experiment based on the RI algorithm
}

\author{
K. Z. Nanjo \\ Earthquake Research Institute, University of Tokyo, 1-1-1 Yayoi, Bunkyo-ku, 113-0032 Tokyo, Japan \\ (Received March 19, 2010; Revised January 5, 2011; Accepted January 5, 2011; Online published March 4, 2011)
}

\begin{abstract}
An earthquake forecast testing experiment for Japan, the first of its kind, is underway within the framework of the Collaboratory for the Study of Earthquake Predictability (CSEP) under a controlled environment. Here we give an overview of the earthquake forecast models, based on the RI algorithm, which we have submitted to the CSEP Japan experiment. Models have been submitted to a total of 9 categories, corresponding to 3 testing classes (3 years, 1 year, and 3 months) and 3 testing regions. The RI algorithm is originally a binary forecast system based on the working assumption that large earthquakes are more likely to occur in the future at locations of higher seismicity in the past. It is based on simple counts of the number of past earthquakes, which is called the Relative Intensity (RI) of seismicity. To improve its forecast performance, we first expand the RI algorithm by introducing spatial smoothing. We then convert the RI representation from a binary system to a CSEP-testable model that produces forecasts for the number of earthquakes of predefined magnitudes. We use information on past seismicity to tune the parameters. The final submittal consists of 36 executable computer codes: 4 variants corresponding to different smoothing parameters for each of the 9 categories. They will help to elucidate which categories and which smoothing parameters are the most meaningful for the RI hypothesis. The main purpose of our participation in the experiment is to better understand the significance of the relative intensity of seismicity for earthquake forecastability in Japan.
\end{abstract}

Key words: Earthquake, forecasting, seismicity, Japan, statistics.

\section{Introduction}

The wide variety of approaches, which have so far been applied to earthquake forecasting, can be grouped into two major categories (Turcotte, 1991). The first consists of approaches based on empirical observations of precursory changes in seismicity, ground motions and other quantities, and many others. Their main purpose is to provide reliable short-term forecasts (days to months) on a consistent basis. No promising approach has so far been identified, and the subject is beyond the focus of the present paper.

Approaches of the second category, aimed at longer-term forecasts, have larger potential for earthquake forecasting. A promising approach is one that is based on statistical patterns of seismicity. The Earth's crust has an extremely complex structure, and it is generally accepted that earthquakes are a chaotic phenomenon (Turcotte, 1997). Therefore, like weather forecasting, earthquake forecasting should be considered on a statistical basis (Rundle et al., 2003). A number of scientists have systematically developed statistical algorithms. A school of Russian researchers have studied seismic activation using the "CN" algorithm for a number of strong earthquakes in California and Nevada and using the "M8" algorithm for magnitude $M>8$ earthquakes worldwide (e.g., Keilis-Borok, 1990; Keilis-Borok and Rotwain,

Copyright (C) The Society of Geomagnetism and Earth, Planetary and Space Sciences (SGEPSS); The Seismological Society of Japan; The Volcanological Society of Japan; The Geodetic Society of Japan; The Japanese Society for Planetary Sciences; TERRAPUB.

doi: $10.5047 / \mathrm{eps} .2011 .01 .001$
1990; Keilis-Borok and Kossobokov, 1990; Keilis-Borok and Soloviev, 2003). Wyss and others (e.g., Wyss, 1997; Wyss and Martirosyan, 1998; Wyss and Wiemer, 2000) found seismic quiescence related to the Armenian and Landers earthquakes using a parameter called the $Z$-value. The method has also been applied to the 1995 Kobe earthquake (Enescu and Ito, 2001). A new algorithm, based on the Pattern Informatics (PI) method, has been proposed by Rundle and coworkers (Rundle et al., 2002, 2003; Tiampo et al., 2002; Holliday et al., 2005, 2007; Nanjo et al., 2006a, b, c). The PI method has been used to detect seismic activation or quiescence and to make earthquake forecasts for California, Japan, and worldwide.

A much simpler alternative is to use the Relative Intensity (RI) of seismicity, or the count of the number of earthquakes in the past. RI stands on the premise that earthquakes are more likely to occur in the future where historical seismicity is higher than elsewhere (Tiampo et al., 2002). As we describe in the present paper, RI can be modified into a smoothed seismicity model. The Proximity to Past Earthquakes (Rhoades and Evison, 2004), Cellular Seismology (Kafka, 2002) and others (e.g., Kagan and Jackson, 2000; Kossobokov, 2004; Helmstetter et al., 2006, 2007) also belong to the category of smoothed seismicity models, although they offer slightly different representations of the same basic hypothesis. Note that temporal changes in seismicity rates are not taken into account in the RI forecast generation. Previous studies indicate that RI has considerable forecast performance despite its simplicity (Rundle $e t$ 


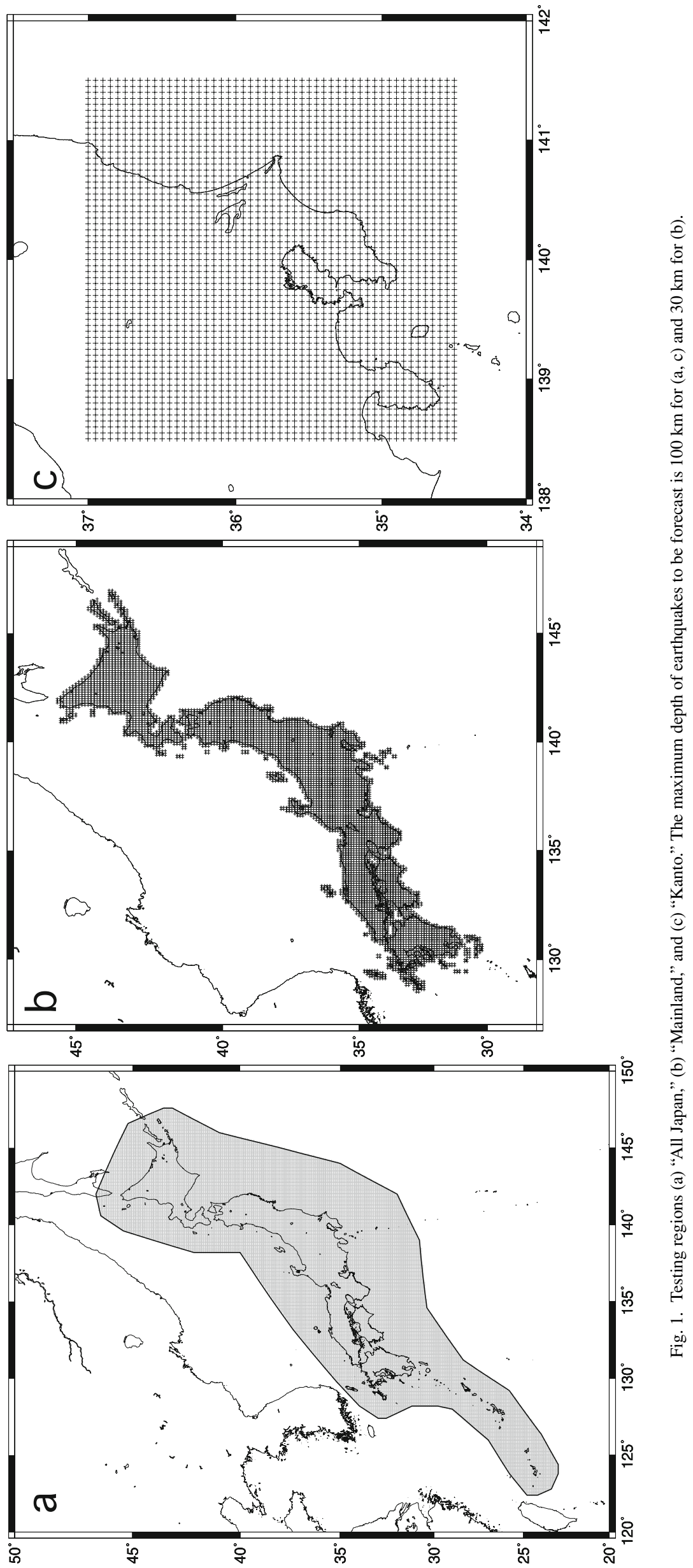


al., 2002, 2003; Tiampo et al., 2002; Holliday et al., 2005, 2006a, b; Nanjo et al., 2006a, b, c; Zechar and Jordan, 2008). The challenge we face is to move toward a systematic, prospective testing of the RI hypothesis under a well-controlled environment.

Amid resurgence in earthquake predictability research, the working group on Regional Earthquake Likelihood Models (RELM) established a facility for prospective testing of scientific earthquake predictions in California (Field, 2007 and reference therein). It was succeeded by an international partnership to develop a Collaboratory for the Study of Earthquake Predictability (CSEP), designed to support a global program of research on earthquake predictability (Jordan, 2006). Prospective testing experiments are underway, under the CSEP framework, in California and elsewhere (http://www.cseptesting.org/). Japan is one of the newly designated regions. The Japan area is characterized by one of the highest seismic risks in the world, with very strong earthquakes of magnitudes $M$ up to 8 or larger occurring offshore and up to 7 or larger occurring inland. To make the most of this condition, a CSEP prospective testing experiment, hosted by the Japanese testing center, was officially launched on 1 November 2009 (Nanjo et al., 2011 this issue). The experiment consists of 12 categories, corresponding to 4 testing classes (1 day, 3 months, 1 year and 3 years) and 3 testing regions, each called "All Japan," "Mainland," and "Kanto" (Fig. 1). Details of the experiment's "Rules of the Game" are given on the website: http://wwweic.eri.u-tokyo.ac.jp/ZISINyosoku/.

In this paper, we present an overview of the RI-based models that we have submitted to the testing center for 9 categories, corresponding to the 3-year, 1-year and 3-month classes and all three testing regions. We have submitted a total of 36 models: 4 variants, corresponding to slightly different representations of the RI hypothesis, for each of the 9 categories. They will help to elucidate which categories and which representations are the most meaningful for the RI hypothesis. The main purpose of our participation in the CSEP experiment is to better understand the significance of the relative intensity of seismicity for earthquake forecastability.

\section{Evidence in Support of RI as a Seismicity Fore- cast Method}

$\mathrm{RI}$ is a very simple algorithm, but it offers a viable approach to earthquake forecasting. Evidence in support of RI comes from three lines summarized below.

\subsection{Advantage of RI over random forecasting}

The RI method, along with the PI method, has been applied to prospective forecasting in a variety of tectonic regimes such as California and Japan, as well as worldwide (e.g., Rundle et al., 2002, 2003; Tiampo et al., 2002; Holliday et al., 2005; Nanjo et al., 2006a, b, c). The output is a map of areas, within the seismogenic region, where earthquakes are forecast to occur within a 10-year time interval in the future. ROC (Relative Operational Characteristics) diagrams (Mason, 2003) and log-likelihood tests have indicated that both methods outperform random guessing under most circumstances.

\subsection{RI forecast associated with large earthquake oc- currence}

Holliday et al. (2006a, b) showed, in retrospective testing for California using ROC diagrams, that PI and RI had comparable accuracy at spatial forecasting (Mason, 2003). They investigated the relative forecast accuracies of PI and RI as a function of time and found that their time variations were highly correlated with the occurrence of large earthquakes: RI outperformed PI during time intervals after 1960 within which $M \geq 6$ earthquakes occurred. They also found that their approach was applicable to the Sumatra region and showed that RI performed better than PI during time intervals after 1980 within which $M \geq 8$ earthquakes occurred. These studies suggest that RI is more effective than PI in forecasting large earthquakes.

2.3 Significant advantage of RI over the U.S. Geological Survey National Seismic Hazard Map (NSHM)

Zechar and Jordan (2008) presented a method for testing alarm-based earthquake predictions by using the Molchan diagram (Molchan, 1990), which is a plot of the miss rate $v$ as a function of the fraction $\tau$ of space-time occupied by alarm. To illustrate the method, they took the example of a 10 -year experiment by Rundle et al. $(2002,2003)$ to predict $M \geq 5$ earthquakes in California, and tested forecasts from three models: RI, PI, and the NSHM (a model that comprises seismicity smoothed over distances as large as $60 \mathrm{~km}$, zones of background seismicity, and explicit fault information). The authors used the RI alarm function as the prior distribution, and computed the Molchan trajectories for the PI and NSHM forecasts. The Molchan trajectories for PI and the NSHM were close to the descending diagonal, indicating that neither PI nor the NSHM provided significant performance gains over the RI reference model.

Their Molchan diagram, however, presents an incomplete test where only one forecast model (RI) was considered for setting up the null hypothesis. We used the same data and program, given as part of their online article, and took the NSHM as a reference. Figure 2 shows that both PI and RI lie far below the descending diagonal at $>95 \%$ confidence $(\alpha<5 \%)$ in the range $v=0.0-0.5$. This means that both PI and RI can deliver performance that is statistically superior to the NSHM at low miss rates $v$, even though RI is the simplest algorithm among the three. When we took PI as a reference, we found that neither RI nor the NSHM provided significant performance gains over the PI reference model.

The challenge that remains is to depart from specific case studies like this one and move toward a systematic, prospective testing under the well-controlled environment of the CSEP Japan experiment.

\section{Formulation}

\subsection{Alarm-based RI and its modification}

In this section, we first give basics of the RI algorithm and then describe how we have modified it by introducing spatial smoothing of seismicity. This modification does not violate the RI hypothesis. Rather, our idea was to investigate whether the introduction of smoothing into RI modeling could enhance the performance of earthquake forecasting. A majority of seismicity-based forecast models use smoothing (Kagan and Jackson, 2000; Kafka, 2002; 


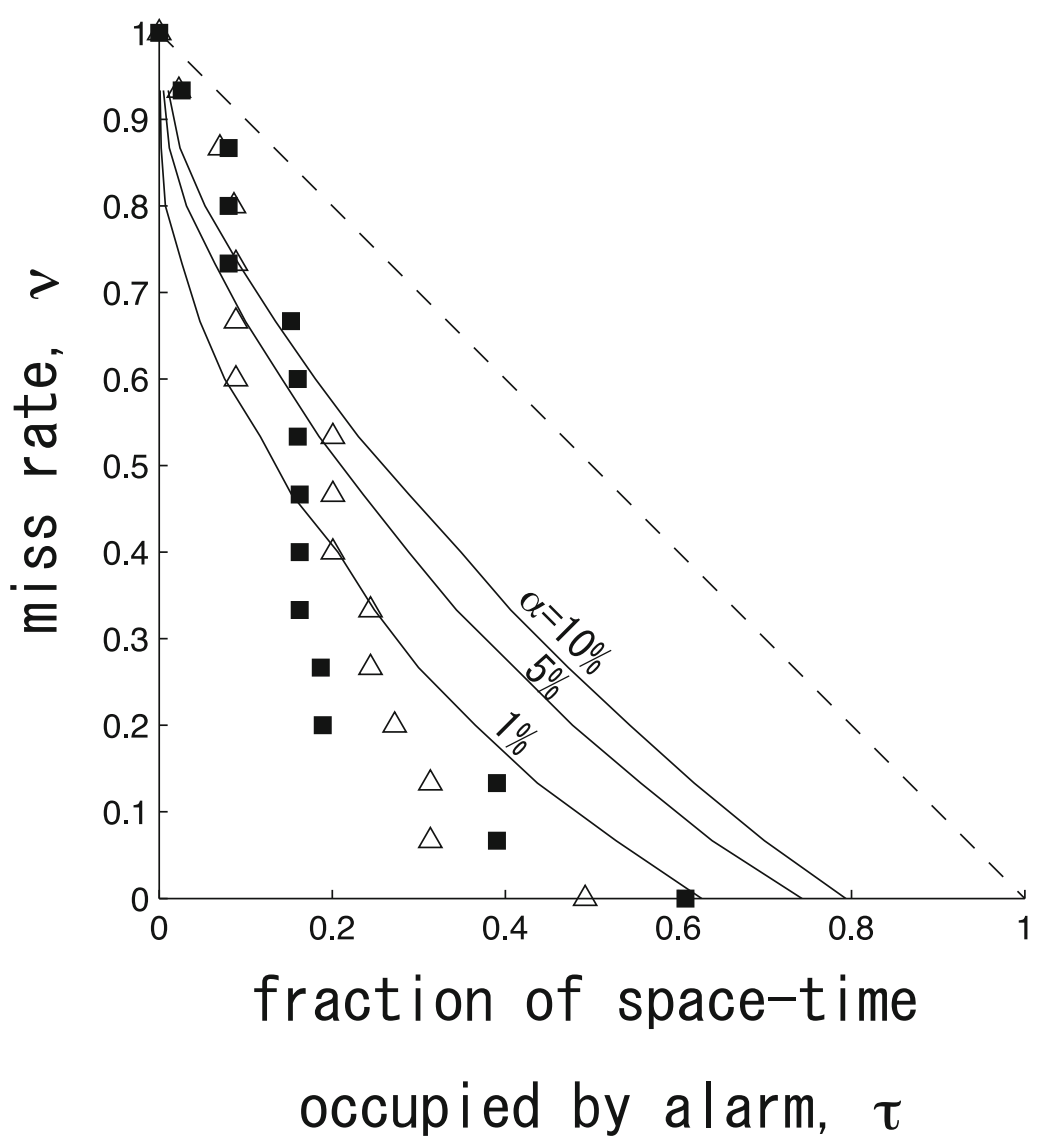

Fig. 2. Molchan trajectory analysis of RI (squares) and PI (triangles) relative to the NSHM reference model. A Molchan trajectory refers to the plot of the miss rate $v$ against the fraction $\tau$ of space-time occupied by alarm. Also shown in the plot are the $\alpha=1,5$, and $10 \%$ confidence boundaries. Data points lying below these boundaries reject the alarm region null hypothesis. In this plot, both PI and RI are significantly better than the NSHM at forecasting future earthquakes in the range $v=0.0-0.5$ at the $95 \%$ confidence level (or $\alpha<5 \%$ ). We used the same data and program as in the online supplement to the Zechar and Jordan (2008) paper.

Kossobokov, 2004; Rhoades and Evison, 2004; Helmstetter et al., 2006, 2007). Introduction of smoothing into modeling is meant to reflect the fact that earthquakes are more prone to occur in the neighborhood of locations where earthquakes happened in the past. A physical basis for this likelihood enhancement can be found in the concept of fault interactions via the Coulomb Failure Function (CFF). The locations of subsequent earthquakes occurring off the main shock fault can be explained by spatial variations of the CFF (e.g., Stein et al., 1992).

The influence of an earthquake is neither isotropic nor uniform. As a simple solution, however, we use uniform and isotropic smoothing in the wake of previous studies (Nanjo et al., 2006a; Holliday et al., 2007). We do not consider distance-dependent smoothing, although most of the existing smoothing procedures take distance into account (e.g., Kagan and Jackson, 2000). This is only an initial attempt, and future modifications of our RI modeling may involve the introduction of distance-dependent and anisotropic smoothing. Ogata (2011 this issue), for example, modified the space-time variant of the epidemic type aftershock sequence (ETAS) model (e.g., Ogata, 1998) to deal with anisotropic clustering.

There are still more reasons in favor of smoothing. First, all earthquake catalogs that researchers use have limited time coverage. For example, the data we use start only from
1998. This means that, on a high-resolution grid such as the one used in the CSEP Japan experiment, many bins can remain statistically "empty," even in areas of high seismicity. Smoothing helps to compensate for such insufficiency of data. Second, uncertainties in epicentral locations can be larger than the grid size, particularly in older parts of catalogs. Smoothing can be used to account for such location errors. In our case, however, this second reason does not apply, because the location errors are smaller than the grid size. At any rate, the fundamental question is whether smoothing enhances the performance of earthquake forecasting.

The RI formulation involves two periods: a forecast period from $t_{2}$ to $t_{3}\left(t_{2}<t_{3}\right)$, which is fixed under a predefined rule, and a learning period from $t_{0}$ to $t_{1}\left(t_{0}<t_{1}<t_{2}\right)$, which may be defined by the modeler. We forecast seismicity during the period from $t_{2}$ to $t_{3}$ using information on earthquakes that occurred during the learning period.

In the original RI approach, the first step is to divide the region of interest into a grid of boxes. We count the number of earthquakes, of $M$ larger than the lower cutoff magnitude $\left(M_{\mathrm{L}}\right)$, that occurred in the $i$ th box during the period from $t_{0}$ to $t_{1}$, and denote it by $n_{i}\left(t_{0}, t_{1}, M_{\mathrm{L}}\right)$. The corresponding number is counted for all boxes. The relative share of the number, or the relative intensity of seismicity, is defined by $P_{i}\left(t_{0}, t_{1}, M_{\mathrm{L}}\right)=n_{i}\left(t_{0}, t_{1}, M_{\mathrm{L}}\right) / \sum_{j} n_{j}\left(t_{0}, t_{1}, M_{\mathrm{L}}\right)$, where 
the sum over $j$ is taken over all boxes. RI hypothesizes that large earthquakes are likely to occur, during the period from $t_{2}$ to $t_{3}$, in boxes with large $P_{i}\left(t_{0}, t_{1}, M_{\mathrm{L}}\right)$ values. This type of approach is called alarm-based forecast. RI forecast is binary: an earthquake is forecast to occur in the $i$ th box if $P_{i}\left(t_{0}, t_{1}, M_{\mathrm{L}}\right)$ exceeds a given threshold, whereas it is forecast not to occur if $P_{i}\left(t_{0}, t_{1}, M_{\mathrm{L}}\right)$ is smaller than the threshold. The standard approach to evaluate a binary forecast is to use the Molchan diagram (Molchan, 1990) and the ROC diagram (Mason, 2003).

We modify the original RI approach by introducing a process of data binning. This idea was first introduced to improve PI forecasts (Nanjo et al., 2006a; Holliday et al., 2007), but we take a slightly revised approach to RI modeling. We introduce a smoothing parameter $(S)$ and count the number $\left(n_{\mathrm{sb}}\right)$ of boxes that lie within a distance $S$ of the center of the $i$ th box: the larger the parameter $S$, so is the number $n_{\mathrm{sb}}$. Data binning is implemented by averaging the seismicity in the $i$ th box and in the $n_{\mathrm{sb}}$ surrounding boxes. For example, if an earthquake of $M \geq M_{\mathrm{L}}$ occurred in the $i$ th box during the period from $t_{0}$ to $t_{1}$, we assign $\left(n_{\mathrm{sb}}+1\right)^{-1}$ to the ensemble of the $i$ th box and the $n_{\mathrm{sb}}$ boxes that surround it. This smoothens spatial patterns of seismicity: the larger the $S$ value, the smoother. When $S$ is so small that $n_{\mathrm{sb}}=0$, the situation becomes the same as the original approach with no smoothing.

\subsection{Limitation of the CSEP testing}

A limitation of the CSEP testing is that the N-, L-, and Rtests, as defined by the CSEP (Schorlemmer et al., 2007), cannot evaluate a forecast that involves zero-probability boxes if a target earthquake occurs in one of them. To make an RI forecast model testable, we artificially assign the smallest among all non-zero values of $P_{i}\left(t_{0}, t_{1}, M_{\mathrm{L}}\right)$ to every box with $P_{i}\left(t_{0}, t_{1}, M_{\mathrm{L}}\right)=0$. Given that the sum of all probabilities $\sum_{i} P_{i}\left(t_{0}, t_{1}, M_{\mathrm{L}}\right)$ should be equal to 1 and that the number of zero-value boxes can be very large, this procedure can significantly lower the probabilities in the nonzero-value boxes. This is therefore a simple but imperfect process. There is currently no logical basis for assigning a non-zero value to every box with $P_{i}\left(t_{0}, t_{1}, M_{\mathrm{L}}\right)=0$ in the RI framework. We shall address this point in more details in a companion paper by Yamashina and Nanjo (2011 in press), which discusses how best to assign probabilities to zero-value boxes in order to optimize the RI model for earthquake forecasting in Japan.

\subsection{CSEP-testable representation}

Within the CSEP testing framework, any model must forecast the number of earthquakes, $\lambda_{i M}$, that occur in the $i$ th box and fall into the magnitude bin $M$. Each bin represented by $M$ ranges from $M-0.05$ to $M+0.05$. The consecutive magnitude bins are $M=4.0,4.1, \ldots, 9.0$ for the 3-month class and 5.0, 5.1, .., 9.0 for the 1-year and 3-year classes. Our challenge was to convert RI from the original alarm-based forecast to a CSEP-compatible one. Below we briefly explain how we did this.

We first estimate the total number of events with $M \geq$ $M_{\mathrm{L}}$ during the learning period $t_{0}$ to $t_{1}$ and call this $N_{\mathrm{T}}$. We next infer the number of events with $M \geq M_{\mathrm{L}}$ to occur within a time interval of length $\Delta t \equiv t_{3}-t_{2}$ by the formula $N_{\mathrm{T}} \Delta t\left(t_{1}-t_{0}\right)^{-1}$. We finally multiply $P_{i}\left(t_{0}, t_{1}, M_{\mathrm{L}}\right)$ by $N_{\mathrm{T}} \Delta t\left(t_{1}-t_{0}\right)^{-1}$ to estimate the number of events with $M \geq M_{\mathrm{L}}$ that occur in the $i$ th box during the forecast period of length $\Delta t$.

To extrapolate our forecast to any magnitude bin represented by $M_{1} \leq M<M_{2}$, we use the Gutenberg-Richter (GR) frequency-magnitude law:

$$
\log N=A-b m
$$

where the parameters $A$ and $b$ are constants and $N$ is the number of earthquakes with $M \geq m$. Substituting $m=M_{\mathrm{L}}$ and $N=N_{\mathrm{T}} \Delta t\left(t_{1}-t_{0}\right)^{-1} P_{i}\left(t_{0}, t_{1}, M_{\mathrm{L}}\right)$ into Eq. (1), we obtain $A=\log _{10}\left[N_{\mathrm{T}} \Delta t\left(t_{1}-t_{0}\right)^{-1} P_{i}\left(t_{0}, t_{1}, M_{\mathrm{L}}\right)\right]+b M_{\mathrm{L}}$. Substituting this again into Eq. (1) gives $N=10^{\beta(m)}$ where $\beta(m)=\log _{10}\left[N_{\mathrm{T}} \Delta t\left(t_{1}-t_{0}\right)^{-1} P_{i}\left(t_{0}, t_{1}, M_{\mathrm{L}}\right)\right]-b\left(m-M_{\mathrm{L}}\right)$. This is the formula to forecast the number of events with $M \geq m$ that occur in the $i$ th box during the period from $t_{2}$ to $t_{3}$. Subtracting the value of $N=10^{\beta(m)}$ calculated for $m=M_{2}$ from that calculated for $m=M_{1}$, we finally obtain the forecast number $\left(\lambda_{i M}\right)$ of events in the $i$ th box that fall within the bin $M_{1} \leq M<M_{2}$ during the period from $t_{2}$ to $t_{3}: \lambda_{i M} \equiv 10^{\beta\left(M_{1}\right)}-10^{\beta\left(M_{2}\right)}$.

\section{Data}

Following the CSEP "Rules of the Game," the testing center has provided all modelers with a JMA earthquake catalog for them to use in their forecast modeling. The catalog contains earthquakes that occurred from 1965 on, and was complete up to 31 January 2009 as it was provided to the test participants.

A majority of earthquakes form parts of sequences, such as swarms or aftershocks. It is generally recognized that attempts to eliminate earthquake clusters, or decluster them, usually end up imperfect. In fact, "traditional" declustering techniques (e.g., Gardner and Knopoff, 1974; Reasenberg, 1985) are fairly arbitrary in the choice of parameters and often fail to provide satisfactory results. Recently, new stochastic methods have been presented (e.g., Zhuang et al., 2002; Marsan and Lengline, 2008) that address such concerns and seem to be quite suitable for studies that work in a probabilistic framework (like in the present study). Nonetheless, as stated in different ways by a number of researchers, declustering is still not a unique process because there is no unique and authorized definition for mutually dependent events. In the light of this situation, we have decided to avoid the introduction of such ambiguity relevant to declustering, and instead to make forecasts on the basis of a non-declustered catalog (the original catalog where aftershocks and swarms have not been eliminated). Declustering earthquake catalogs for RI-type models presents a major challenge, because no previous study has ever investigated whether it improves forecast ability (Rundle et al., 2002, 2003; Tiampo et al., 2002; Holliday et al., 2005, 2007; Nanjo et al., 2006a, b, c). We shall come back to this point in more details in Section 5.

Seismic networks used for compiling the JMA catalog have gradually been modernized over time. To complement its own nationwide network, the JMA started, in October 1997, real-time processing of waveform data from a number of other seismic networks in Japan. Nowadays, about 
1,200 seismometers are in operation under the JMA hybrid network. These changes have significantly expanded the network coverage and have greatly enhanced earthquake detection capabilities. For model optimization and forecast generation, we restrict our analysis to the period after 1998.

By way of preliminary analysis, we did a simple test of location errors for $M \geq 2$ events from 1998 onward that are listed in the JMA catalog. As we will explain later, the catalog can be considered complete above $M=2$. We found that typical errors were on the order of $1 \mathrm{~km}$ in latitude, longitude, and depth, which is smaller than the grid size. We therefore assume that errors are not taken into account in the input dataset.

In fact, the depth accuracy tends to be poorer in offshore areas. In some cases, the errors are fairly large even in inland regions, because the 1D model used by the JMA does not take lateral velocity heterogeneities into account. For example, a Joint Hypocenter Relocation (JHR) study on the aftershocks of the 2004 Mid-Niigata Prefecture earthquake (Shibutani et al., 2005) showed biases of the original JMA hypocenters of about $3 \mathrm{~km}$, both vertically and horizontally. However, such errors are unlikely to affect the results of this study, because the grid size still remains larger than the location errors (about $3 \mathrm{~km}$ ).

\section{Application to the Japan Experiment}

Previously, RI was used in 10-year experiments to predict earthquakes in California, in Japan, and on a worldwide basis (Rundle et al., 2002, 2003; Tiampo et al., 2002; Holliday et al., 2005, 2007; Nanjo et al., 2006a, b, c). Following these studies, we first applied RI to the long-term (3-year and 1-year) classes. These classes are suitable for the application of RI models, which tend to produce time-invariant forecast patterns, whether the application is based on a nondeclustered catalog, or on the use of declustering as was done by Helmstetter et al. (2006). Because RI models cannot cope with the effects of aftershocks, the application of RI to shorter-term classes presents challenges, but we have applied RI to the 3-month class as well to assess the potentials and limitations of RI-based short-term forecasting. We shall address this point in Section 6.

In computing $\lambda_{i M}$ in an RI-based forecast, the parameters $\left(t_{0}, t_{1}, M_{\mathrm{L}}, b, S\right.$, depth, and the box size) can be tuned by the modeler, whereas $t_{2}$ and $t_{3}$ (and therefore the interval $\Delta t$ ) are predefined by the "Rules of the Game." To tune the parameters, we have used available data on past seismicity. We have also carried out a comparative test to decide whether we should use a declustered or a non-declustered catalog for generating the input. A set of parameters, tuned to produce the best retrospective forecast for the seismicity of a certain time interval in the past, does not necessarily best forecast the seismicity of other time intervals, including intervals in the future. We have therefore preferred to determine the individual parameters independently rather than determine their optimal set by retrospective forecasting. Below we briefly describe the target depth range and the box size, and explain the rationale for the choice of each parameter. All parameter values are summarized in Table 1.

\subsection{Depth range and the box size}

We considered all events down to a depth of $d=100 \mathrm{~km}$ in the forecast generation for the testing regions "All Japan" and "Kanto," because for these regions, forecast should be targeted at earthquakes of $d \leq 100 \mathrm{~km}$ according to the "Rules of the Game". For the same reason, all events down to $30 \mathrm{~km}$ depth were considered for the testing region "Mainland."

The testing center has provided modelers of "All Japan" with a list of nodes (longitude and latitude pairs), at each of which $\lambda_{i M}$ has to be computed. The node spacing is $0.1^{\circ}$ in both latitude and longitude. In RI modeling, we considered a set of boxes sized $0.1^{\circ}$ in both latitude and longitude and centered at each of the prescribed nodes. We repeated the same procedure for "Mainland" and "Kanto," except that the node spacing was $0.05^{\circ}$ for the "Kanto" region. The angles of $0.1^{\circ}$ and $0.05^{\circ}$ roughly correspond to lengths of 10 and $5 \mathrm{~km}$, respectively. Because these lengths are obviously larger than the location errors described in Section 4, the errors were not taken into account during the data binning stage of the modeling.

\subsection{Completeness magnitude}

$M_{\mathrm{L}}$ should desirably be smaller because, as previous studies have indicated, the making of any RI forecast map should ideally involve as small events as possible (e.g., Rundle et al., 2002, 2003; Tiampo et al., 2002; Holliday et al., 2005; Nanjo et al., 2006a, b, c). However, small events more often fail to be detected than larger ones. It is therefore necessary to evaluate the completeness magnitude $\left(M_{\mathrm{C}}\right)$, above which all events can be relied upon to have been catalogued. Various techniques to compute $M_{\mathrm{C}}$ and their practical applications were reviewed by Wiemer and Wyss (2002). A method frequently used is to define $M_{\mathrm{C}}$ as the point of deviation from the GR distribution (Eq. (1)).

We adopt a GR-based approach called the EMR (EntireMagnitude-Range) method (Woessner and Wiemer, 2005), which is implemented in ZMAP, a seismicity analysis software (Wiemer, 2001). To map the distribution of $M_{\mathrm{C}}$, we have used a grid with a node spacing of $0.3^{\circ}$. At each node, we sample the 300 nearest earthquakes and, by setting an upper limit of $100 \mathrm{~km}$ on the distance to sampled earthquakes, exclude low- or no-seismicity areas from the mapping nodes, because larger distances no longer reflect local seismicity.

For "All Japan" and "Kanto," we have considered events of depths $d \leq 100 \mathrm{~km}$ from 1 January 1998 onward to make the $M_{\mathrm{C}}$ map in Fig. 3(a). The polygons in the figure delineate these testing regions. $M_{\mathrm{C}}$ is typically smaller than 2.0 on the mainland of Japan. As is naturally expected, $M_{\mathrm{C}}$ is higher in offshore regions than within the coverage of the seismic network, and exceeds 2.5 more than $100 \mathrm{~km}$ off the shores. In the "Kanto" region including coastal areas, the maximum $M_{\mathrm{C}}$ is about 2.5 . We have therefore chosen $M_{\mathrm{L}}=2.5$ for this region. $M_{\mathrm{C}}$ values of over 3.0 can be observed near the outer boundaries of the "All Japan" region, but we have set $M_{\mathrm{L}}=3.0$ for "All Japan" by visual inspection, because the areas of $M_{\mathrm{C}} \geq 3.0$ are not significant.

We did the same $M_{\mathrm{C}}$ mapping to determine $M_{\mathrm{L}}$ for the "Mainland" region, except that the depth range was limited 
Table 1. Summary of the model parameters used for "All Japan," "Mainland," and "Kanto." $d$, depth range of the events used to generate the forecasts; $b, b$-value of the GR law (Eq. (1)); $t_{0}$, start time of the learning period; $M_{\mathrm{L}}$, lower cutoff magnitude; $S$, smoothing parameter.

\begin{tabular}{cccccccc}
\hline Testing region & Box size & Number of boxes & $d$ & $b$ & $t_{0}$ & $M_{\mathrm{L}}$ \\
\hline All Japan & $0.1^{\circ}$ & 20062 & $0-100 \mathrm{~km}$ & 0.9 & $1 / 1 / 199800: 00: 00$ & 3.0 & $10,30,50$, and $100 \mathrm{~km}$ \\
Mainland & $0.1^{\circ}$ & 5483 & $0-30 \mathrm{~km}$ & 0.9 & $1 / 1 / 199800: 00: 00$ & 2.0 & $10,30,50$, and $100 \mathrm{~km}$ \\
Kanto & $0.05^{\circ}$ & 3111 & $0-100 \mathrm{~km}$ & 0.9 & $1 / 1 / 199800: 00: 00$ & 2.5 & $10,30,50$, and $100 \mathrm{~km}$ \\
\hline
\end{tabular}

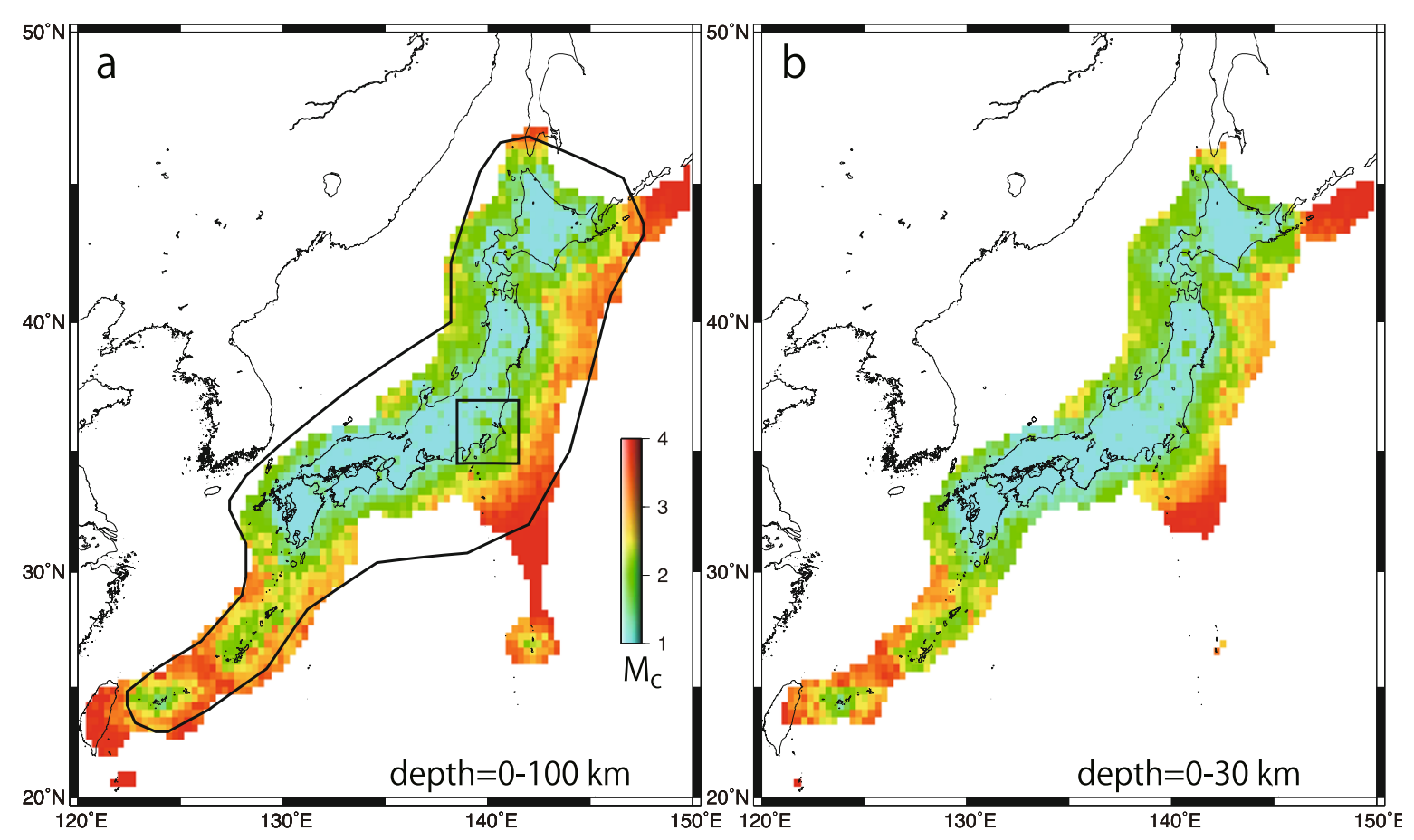

Fig. 3. $M_{\mathrm{C}}$ maps based on events after 1 January 1998 for the depth ranges (a) $d \leq 100 \mathrm{~km}$ and (b) $d \leq 30 \mathrm{~km}$. In panel (a), a polygon and a rectangle delineate the boundaries of the "All Japan" and "Kanto" testing regions, respectively.

to $d=0-30 \mathrm{~km}$ (Fig. 3(b)). On Japan's mainland, the pattern of $M_{\mathrm{C}}$ is much the same as in the case of $d=0-100 \mathrm{~km}$ (Fig. 3(a)). This is natural because, in both cases, a majority of the earthquakes used were shallow inland events. In offshore regions, however, there are some differences. For one thing, $M_{\mathrm{C}}$ tends to be larger in Fig. 3(a) than in Fig. 3(b) along the Pacific Ocean and Philippine Sea coasts. For another, $M_{\mathrm{C}}$ is mapped, in Fig. 3(a), in the waters between the Izu and the Bonin Islands but not in Fig. 3(b). This is partly because deep subduction-zone events were included in the mapping of $M_{\mathrm{C}}$ for Fig. 3(a) but not for Fig. 3(b), and partly because the detection capabilities tend to be poorer for deep events than for shallow events. At any rate, the "Mainland" does not include the offshore regions. We have chosen $M_{\mathrm{L}}=2.0$ by the inspection of Fig. 3(b).

\section{$5.3 b$-value}

According to a recent study (Ishibe and Shimazaki, 2009), $b$ typically takes values of $0.8-1.0$ for earthquakes in Japan. We first examine the validity of this statement by using three datasets: (a) earthquakes of $d \leq 100 \mathrm{~km}$ in and around Japan, or in the testing region "All Japan"; (b) earthquakes of $d \leq 30 \mathrm{~km}$ on Japan's mainland and in coastal areas, or in the testing region "Mainland"; and (c) earthquakes of $d \leq 100 \mathrm{~km}$ in the "Kanto" region. The target period is from 1 January 1998 to 31 January 2009 for all cases. In Fig. 4(a-c), the cumulative number $N$ of earthquakes is shown as a function of $m$. Using the EMR method, we have obtained $b=0.83 \pm 0.07$ and $A=7.38$ for case (a), $b=0.98 \pm 0.03$ and $A=7.07$ for case (b), and $b=0.92 \pm 0.03$ and $A=6.44$ for case (c). The GR relation (Eq. (1)) demonstrated good fit to observation for these parameter values. All $b$-values were estimated by using earthquakes of magnitudes that are larger than the $M_{\mathrm{L}}$ values listed in Table 1 . These results validate the statement that $b$ typically lies between 0.8 and 1.0.

In hazard- and forecast-related projects, the $b$-value in Eq. (1) is either taken as a global constant or is allowed to vary spatially, and there is currently no clear-cut scientific basis to determine which approach is better (e.g., Wiemer and Schorlemmer, 2007). Because RI is based on simple counts of the number of past earthquakes, the $A$-value in Eq. (1) is definitely more important than the $b$-value for forecasting future events. We therefore assume that $b=$ 0.9 is a good enough approximation for highlighting the features of the RI-type approach, and use it for all testing regions.

\subsection{Smoothing parameter}

No recommended value is known for $S$, although we have explained the physical basis and other reasons of importance of this parameter in Section 3. As stated above, we did not tune $S$ by retrospective forecasts of seismicity. We have produced four variants of forecast models, each corre- 

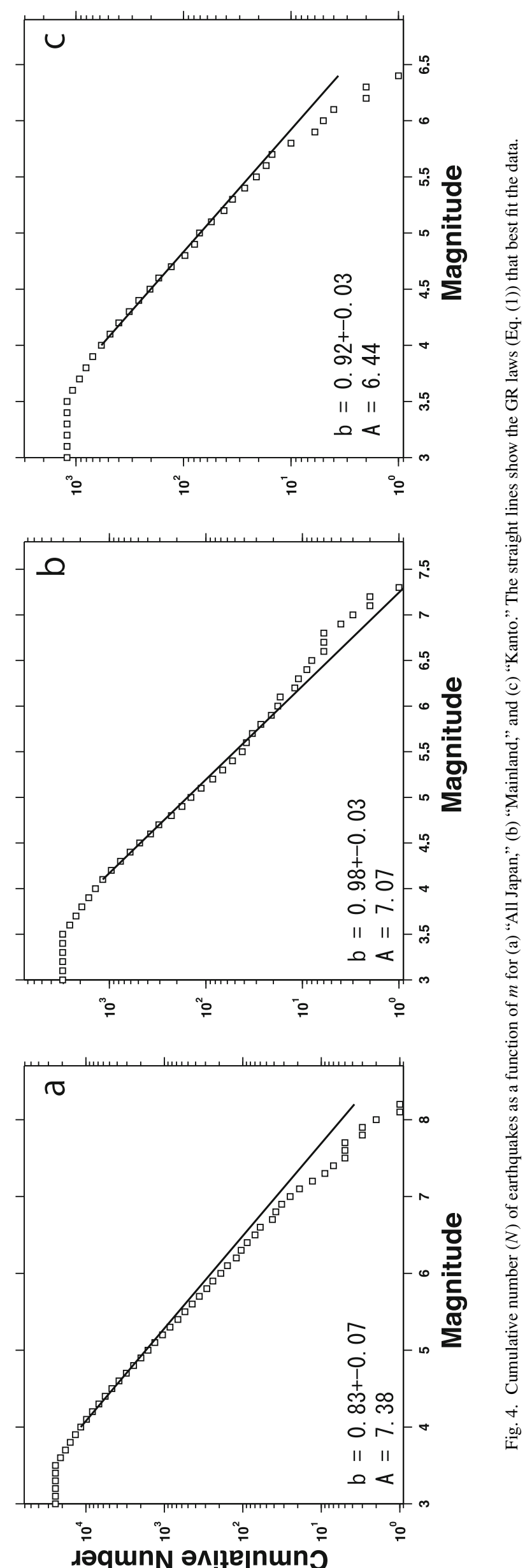

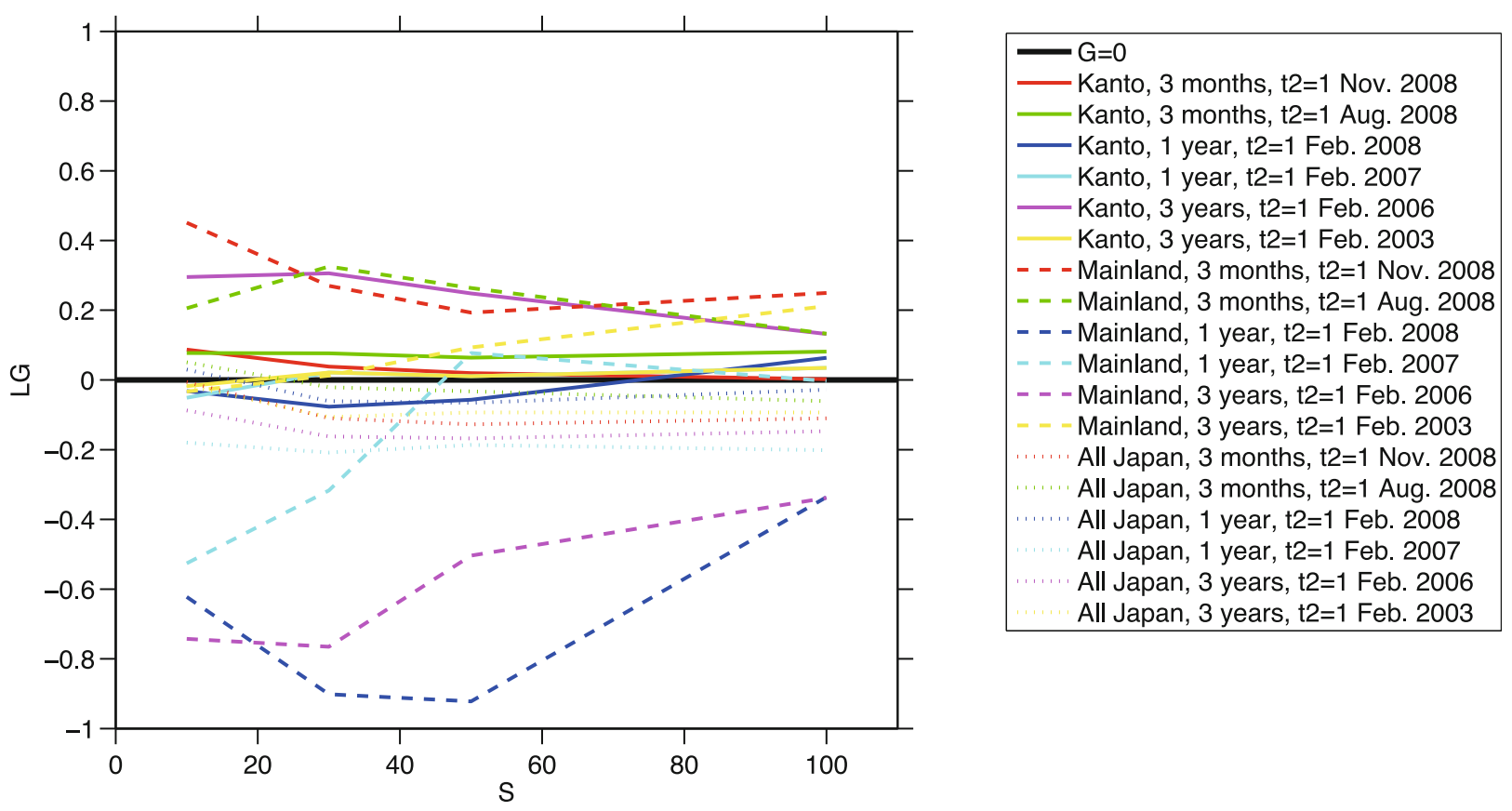

Fig. 5. Logarithm probability gains per earthquake, LG, as a function of the smoothing parameter $S$. See the legends for the controlled test conditions (testing regions, testing classes, and forecast periods).

sponding to $S=10,30,50$, and $100 \mathrm{~km}$.

\subsection{Learning period}

The learning period should preferably be longer in any RI-type forecast modeling (e.g., Rundle et al., 2002, 2003; Tiampo et al., 2002; Holliday et al., 2005; Nanjo et al., $2006 \mathrm{a}, \mathrm{b}, \mathrm{c})$. We therefore set $t_{0}$ as old as 1 January 1998, and used all events up to time $t_{2}$ in the forecast generation: $t_{1}=t_{2}$.

\subsection{Declustering versus non-declustering}

An RI-type model based on a non-declustered catalog may overestimate future seismicity rates near the epicenters of large earthquakes in the past, because aftershocks that dominate seismicity near those epicenters are included in the forecast generation. Declustering earthquake catalogs for use in RI-type forecasts is a challenging subject because, as discussed in Section 4, no clear-cut and authorized definition of aftershocks has so far been agreed upon.

The time-invariant forecast model, discussed by Helmstetter et al. (2006), is essentially an RI model that involves catalog declustering. Unfortunately, however, it is not always easy to investigate whether such a declusteringbased RI algorithm has poorer or better forecast accuracy. This is because declustering reduces the number of earthquakes in a catalog, typically to less than half the original number, although details may depend on the algorithm used. This means that, unless a large smoothing factor is used, the target earthquake locations may very likely fall into "empty" boxes when the region in question has low to moderate seismicity.

Japan, on the contrary, is one of the most seismically active regions in the world, so it offers a precious locale for testing whether non-declustering, or declustering, has better accuracy in retrospective seismicity forecasts. To decluster the JMA catalog from 1998 onward for the depth range $d \leq 100 \mathrm{~km}$, we have decided to use the approach of Reasenberg (1985), because it is simple in idea, is easily implementable being a constituent function of the ZMAP software (Wiemer, 2001), and also because it is popularly used by a large number of researchers (e.g., Wiemer and Schorlemmer, 2007). We recognize that the test results can differ according to what specific method of declustering is used.

Our statistical test is based on log-likelihood (LL) that is used to evaluate the consistency of a forecast (a set of $\lambda_{i M}$ ) with observations (a set of target earthquakes). We define $\mathrm{LL}$ as $\mathrm{LL}=\sum_{i}\left\{-\theta_{i}+\omega_{i} \log \theta_{i}-\log \left(\omega_{i} !\right)\right\}$, where $\theta_{i}$ is the sum of $\lambda_{i M}$ over all target magnitude bins $\left(\theta_{i} \equiv \sum_{M} \lambda_{i M}\right)$ for the $i$ th box, and $\omega_{i}$ is the number of target earthquakes. This is a simplified version of the CSEP test (Schorlemmer et al., 2007). Our test compares forecasts in terms of LL: the larger the LL value, the better the agreement between forecast and observation. A useful measure for comparison here is the logarithm probability gain per earthquake: $\mathrm{LG}=\left(\mathrm{LL}_{\mathrm{nd}}-\mathrm{LL}_{\mathrm{d}}\right) / N_{\mathrm{t}}$, where $N_{\mathrm{t}}$ is the total number of target earthquakes $\left(N_{\mathrm{t}}=\sum_{i} \omega_{i}\right)$, and $\mathrm{LL}_{\mathrm{nd}}$ and $\mathrm{LL}_{\mathrm{d}}$ are the log-likelihoods for the non-declustered and declustered catalogs, respectively. LG was modified from a measure used by Helmstetter et al. (2007). A positive LG $>0$ would indicate that the use of the original, non-declustered catalog has better forecast capabilities than the use of the declustered catalog.

The results are shown in Fig. 5. In generating the forecast, we used the parameter values listed in Table 1 and smoothing parameters of $S=10,30,50$, and $100 \mathrm{~km}$. The parameters in Table 1 were selected on the basis of the nondeclustering case, but we have assumed that they are applicable to the declustering case as well. We conducted tests for the "Kanto," "Mainland," and "All Japan" regions. We considered three testing classes, with two different forecast periods for each case: the starting days were $t_{2}=1 \mathrm{Jan}$ - 


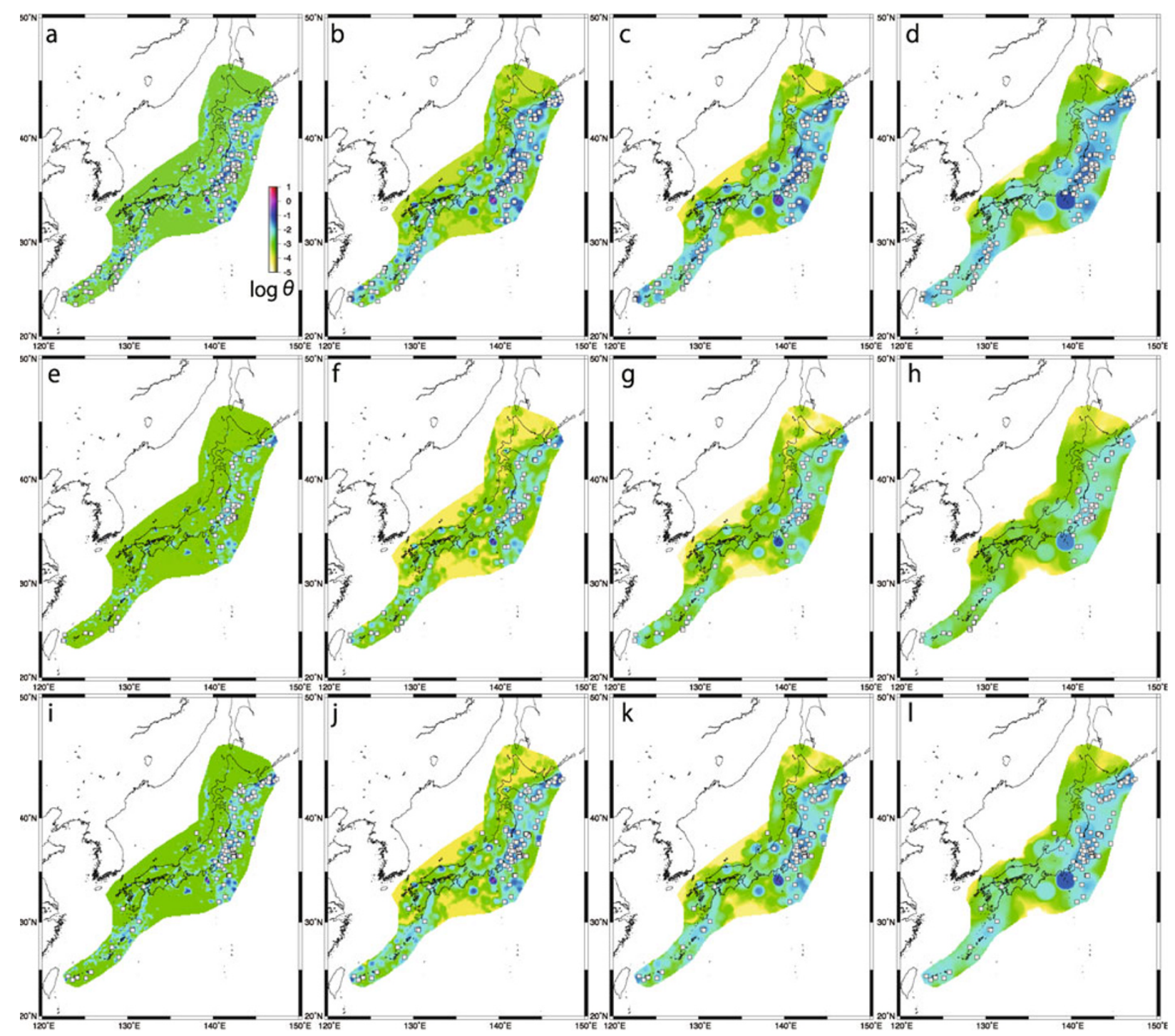

Fig. 6. Retrospective forecasts for the testing region "All Japan." The top, middle, and bottom rows correspond to the 3-year (a, b, c, d), 1-year (e, f, g, h), and 3-month (i, j, k, l) classes. The four columns correspond to smoothing parameters of $S=10$ (a, e, i), 30 (b, f, j), 50 (c, g, k), and $100 \mathrm{~km}(\mathrm{~d}, \mathrm{~h}$, 1), respectively, from left to right. The maps show color contours (in logarithm) of the cumulative number $\left(\theta_{i}\right)$ of $5 \leq M \leq 9$ forecast events for the 3 -year and 1-year classes and $4 \leq M \leq 9$ events for the 3-month class. The squares indicate the 168 earthquakes of $M \geq 5$ that actually happened between 1 February 2006 and 31 January 2009 in the top row panels, the 78 earthquakes of the same magnitude range between 1 February 2008 and 31 January 2009 in the middle row panels, and the $112 M \geq 4$ earthquakes between 1 November 2008 and 31 January 2009 in the bottom row panels.

uary 2003 and 1 January 2006 for the 3 -year class, $t_{2}=1$ January 2007 and 1 January 2008 for the 1-year class, and $t_{2}=1$ August 2008 and 1 November 2008 for the 3-month class. We have therefore tested a total of 18 cases.

The resulting LG values are illustrated in Fig. 5 as a function of $S$. The data show considerable scatters, and LG is almost equally likely to take positive and negative values. In other words, the use of the declustered catalog has, in some cases, better abilities to retrospectively forecast seismicity than the use of the original, non-declustered catalog, but the reverse is true in other cases. Further, LG does not vary significantly with $S$, which means that smoothing seldom affects the relationship between non-declustering and declustering in terms of the forecast accuracy.

To conclude, declustering a seismic catalog does not necessarily improve the forecast capabilities of our RI-based approach. There is therefore no clear-cut scientific basis for preferring either the use or the non-use of declustering. As discussed in Section 4, declustering so far remains an imperfect and unauthorized procedure, and so we prefer to avoid the introduction of ambiguity relevant to declustering. This is why we have decided to use the original, nondeclustered catalog.

\section{Final Models}

Based on the RI hypothesis, we prospectively forecast the number $\left(\lambda_{i M}\right)$ of earthquakes at each node for each of the magnitude bins $4 \leq M \leq 9$ for the predefined, consecutive 3-month periods (starting at $t_{2}=1$ November 2009, 1 February $2010, \ldots$... Similarly, we forecast the corresponding number for each of the magnitude bins $5 \leq M \leq 9$ for the predefined, consecutive 1-year periods (starting at 


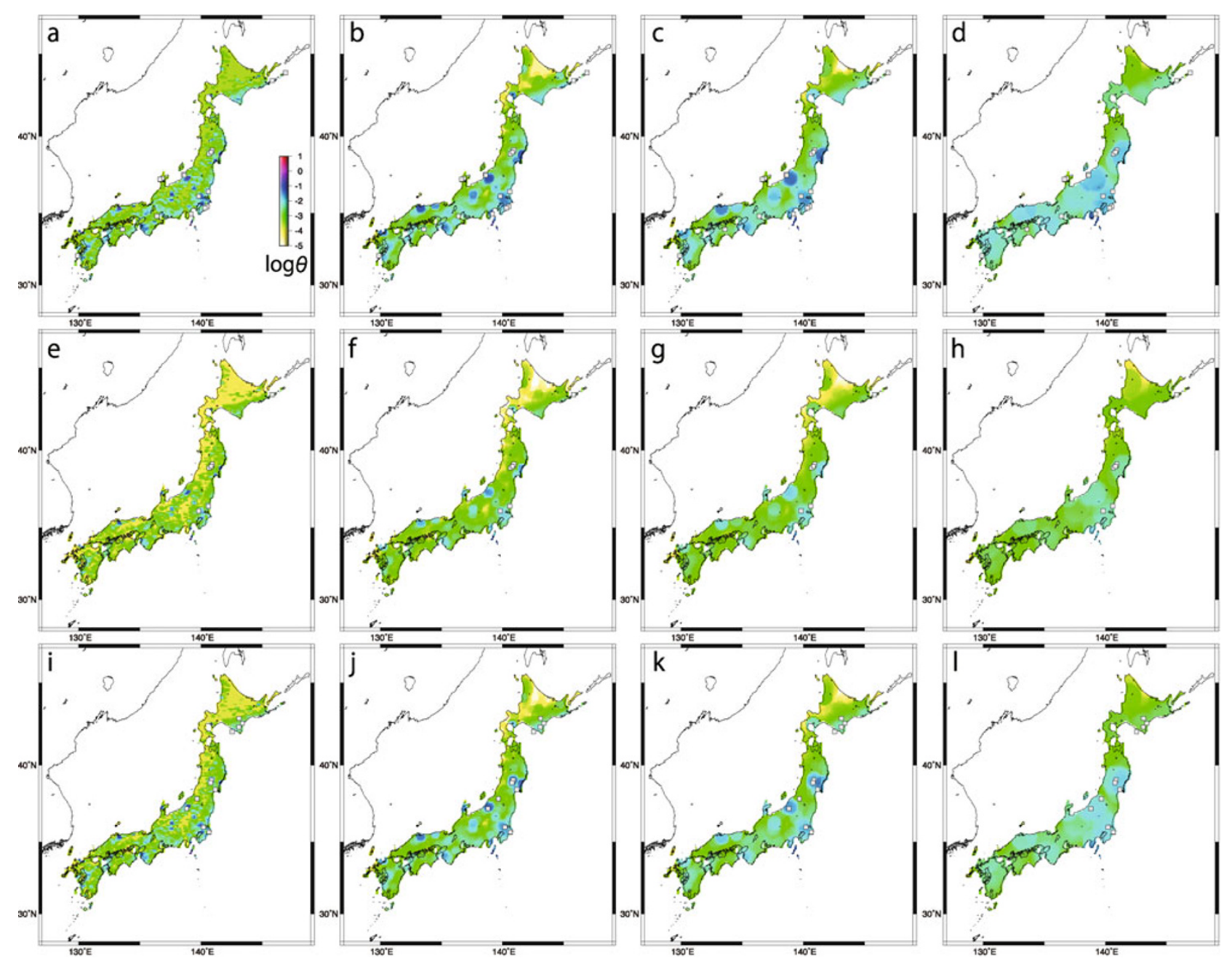

Fig. 7. Same as in Fig. 6 for the "Mainland" testing region. The number of earthquakes (squares) that actually happened during the forecast periods is 21,8 , and 12 for the 3 -month, 1-year, and 3-year classes, respectively.

$t_{2}=1$ November 2009, 1 November $2010, \ldots$ ) and a 3year period ( $t_{2}=1$ November 2009). The combination of these testing classes and the 3 testing regions, "All Japan," "Mainland," and "Kanto," defines a total of 9 forecast categories. For each category, we submitted 4 executable computer codes, corresponding to the different smoothing parameters, to the Japanese testing center. By creating a total of 36 models, we have intended to investigate which categories and which smoothing parameters were the most (or the least) meaningful for the RI hypothesis.

For RI modeling, we set the parameters as listed in Table 1. The time $t_{3}$ is fixed at $t_{2}+\Delta t(\Delta t=3$ months, 1 year, and 3 years) for the 3 testing classes. In forecast implementation, for each given set of $t_{2}$ and $t_{3}$, we equated $t_{1}$ to $t_{2}$ and asked the testing center to provide a JMA catalog that contained earthquakes up to $t_{1}\left(=t_{2}\right)$ as the input information.

Figure 6 shows images of the models submitted for the testing region "All Japan": the 3-year, 1-year, and 3-month classes were used to create the images in the top, middle, and bottom rows, respectively. The four columns correspond to the smoothing parameters of $S=10,30,50$, and
$100 \mathrm{~km}$, respectively, from left to right. To create these images, we used the non-declustered (original) catalog up to 31 January 2009. The time $t_{1}\left(=t_{2}\right)$ was set at 1 February 2006 for the 3-year class, 1 February 2008 for the 1-year class, and 1 November 2008 for the 3-month class. The end time $t_{3}$ was set at 1 February 2009 for all forecast period lengths. The maps show the cumulative number $\left(\theta_{i}\right)$ of forecast events $\left(\theta_{i} \equiv \sum_{M} \lambda_{i M}\right)$ in the magnitude range $5 \leq M \leq 9$ for the 3 - and 1 -year classes and $4 \leq M \leq 9$ for the 3-month class. The total number of forecast earthquakes $\left(\sum_{i} \theta_{i}\right)$ was $205.4,64.0$ and 127.8 for the 3-year, 1-year and 3-month classes, respectively. The squares indicate the 168 $M \geq 5$ earthquakes, $78 M \geq 5$ earthquakes and $112 M \geq 4$ earthquakes that actually happened during the forecast periods of the 3-year, 1-year and 3-month classes, respectively. Visual inspection shows that the RI retrospective forecasts were generally successful in all classes.

A notable exception is the Miyakejima Island to the south of Tokyo (marked in red in Fig. 6(a)). An earthquake swarm, associated with volcanic eruptions on the island, started on 26 June 2000. Since then, there have been 74 earthquakes of $5 \leq M<6$ and 6 earthquakes of $M \geq 6$. 


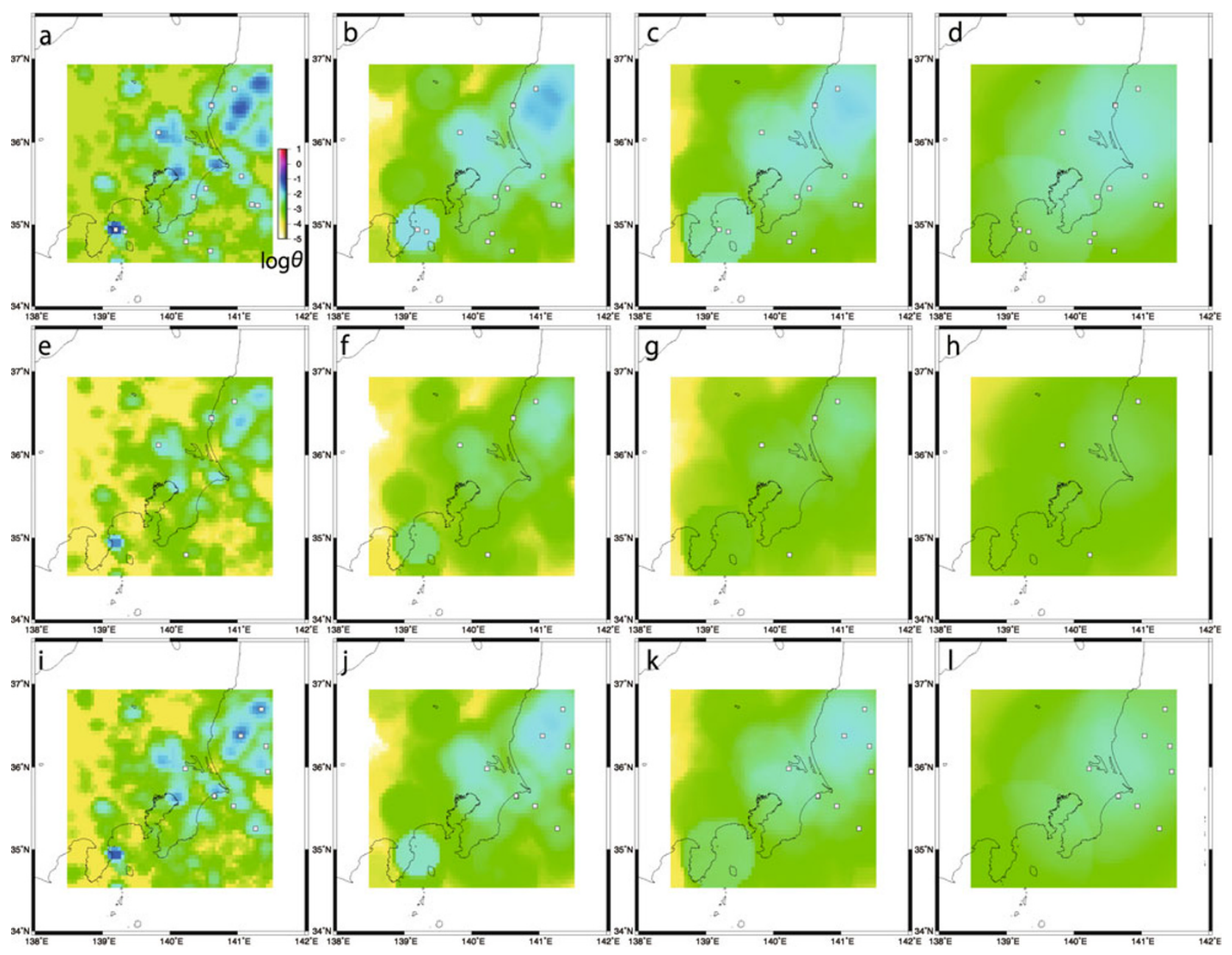

Fig. 8. Same as in Fig. 6 for the "Kanto" testing region. The number of earthquakes (squares) that actually happened in the forecast periods is 9, 5, and 14 for the 3-month, 1-year, and 3-year classes, respectively.

This swarm enhanced the forecast seismicity rates on and around the Miyakejima Island, whereas no earthquake occurred in the target magnitude ranges during the forecast periods. This exemplifies why more elaborated models are needed for all classes, especially for the short-term, 3month class, because our approach cannot take into account earthquake swarms such as this one. Despite this small incongruence, however, visual inspection basically seems to at least justify the use of our approach as a reference forecast model that can be invoked for comparative tests such as the one under the CSEP environment.

Images for the "Mainland" and "Kanto" regions are given in Figs. 7 and 8 respectively. For the former, the total number $\left(\sum_{i} \theta_{i}\right)$ of forecast events is $38.9,12.3$, and 24.9 for the 3-year, 1-year, and 3-month classes, respectively, and for the latter, the corresponding numbers are 11.5, 3.8, and 7.62, respectively. Again, general agreement between forecast and reality is visible in all images, even in the ones for the 3-month class.

\section{Summary and Discussion}

This paper presents at least two very important implications. First, the RI algorithm has most commonly been regarded as a reference against which to test other forecast models within the alarm-based framework. We have expanded RI from the original, alarm-based approach to a more general one based on probabilities. RI has thus evolved into a natural reference for comparative tests with any type of forecast models. Such tests will give an important answer to the question: "Does any specific forecast model give more information on earthquakes to happen in the future than just the known spatial distribution of seismicity rates in the past?"

Second, we have incorporated spatial smoothing of seismicity rates into our RI-type models using four different values of the smoothing distance parameter $S$. Our goal is to understand which smoothing distance produces the best performance in prospective earthquake forecasting.

Smoothing also has negative effects. Seismicity is usually strongly concentrated in the neighborhood of faults. Smoothing "redistributes" seismicity rates by imparting them to less active areas outside of faults. When different forecast models are compared, therefore, it is not recommendable to use a reference model with too heavy smoothing. The significant advantage of RI over the NSHM (Fig. 2) may, accordingly, be an artifact of a similar effect, 
because both PI and RI have much lower degrees of smoothing than the NSHM. This is similar to the advantage of just any forecast model over a uniform reference model: practically any model is expected to lie far below the diagonal in that case. To better assess the effects of smoothing on prospective forecasting, we have created a variety of RIbased models with different smoothing distances.

In summary, the RI models we have submitted allow for a systematic test of the hypothesis that the relative intensity of past seismicity based on simple counts can be used to forecast future moderate-to-large earthquakes in Japan. A possible future modification of RI modeling includes the incorporation of regional variations in the $b$-value (Wiemer and Schorlemmer, 2007), whereas in the present study, we used a constant $b=0.9$ for all testing regions. Another possible modification is the use of a tapered Gutenberg-Richter law with a corner magnitude (Helmstetter et al., 2007) to avoid overestimating the forecast number of large events, whereas we have taken the standard GR formula of Eq. (1). It might be of interest to compare the currently implemented model with one with the proposed modifications to investigate whether those modifications significantly improve the forecasts of future seismicity. Although these possible modifications remain yet to be done, the results that we will obtain through the ongoing prospective forecast experiment in Japan are expected to provide essential materials for understanding the significance (or insignificance) of the simple relative intensity (RI) of seismicity for earthquake forecastability.

Acknowledgments. The author thanks B. Enescu and another reviewer for suggestions on improving the present paper and the Japan Meteorological Agency for the earthquake catalog. The figures (Figs. 1, 3, 6, 7, and 8) were created using GMT (Wessel and Smith, 1991). This work was sponsored by the Special Project for Earthquake Disaster Mitigation in Tokyo Metropolitan Area from the Ministry of Education, Culture, Sports, Science and Technology of Japan.

\section{References}

Enescu, B. and K. Ito, Some premonitory phenomena of the 1995 Hyogo-ken Nanbu earthquake: seismicity, b-value and fractal dimension, Tectonophysics, 338(3-4), 297-314, doi:10.1016/S00401951(01)00085-3, 2001.

Field, E. D., Overview of the working group for the development of Regional Earthquake Likelihood Models (RELM), Seismol. Res. Lett., 78(1), 7-16, doi:10.1785/gssrl.78.1.7, 2007.

Gardner, J. K. and L. Knopoff, Is the sequence of earthquakes in southern California, with aftershocks removed, Poissonian?, Bull. Seismol. Soc. Am., 64(5), 1363-1367, 1974.

Helmstetter, A., Y. Y. Kagan, and D. D. Jackson, Comparison of short-term and time-independent earthquake forecast models for Southern California, Bull. Seismol. Soc. Am., 96, 90-106, doi:10.1785/0120050067, 2006.

Helmstetter, A., Y. Y. Kagan, and D. D. Jackson, High-resolution timeindependent grid-based forecast for $\mathrm{M} \geq 5$ earthquakes in California, Seismol. Res. Lett., 78(1), 78-86, doi:10.1785/gssrl.78.1.78, 2007.

Holliday, J. R., K. Z. Nanjo, K. F. Tiampo, J. B. Rundle, and D. L. Turcotte, Earthquake forecasting and its verification, Nonlin. Proc. Geophys., 12, 965-977, 2005.

Holliday, J. R., J. B. Rundle, K. F. Tiampo, and D. L. Turcotte, Using earthquake intensities to forecast earthquake occurrence times, Nonlin. Proc. Geophys., 13, 585-593, 2006 a.

Holliday, J. R., J. B. Rundle, D. L. Turcotte, W. Klein, K. F. Tiampo, and A. Donnellan, Space-time clustering and correlations of major earthquakes, Phys. Rev. Lett., 97, 238501, doi:10.1103/PhysRevLett.97.238501, 2006b.
Holliday, J. R., C. Chen, K. F. Tiampo, J. B. Rundle, D. L. Turcotte, and A. Donnellan, A RELM earthquake forecast based on Pattern Informatics, Seismol. Res. Lett., 78(1), 87-93, doi:10.1785/gssrl.78.1.87, 2007.

Ishibe, T. and K. Shimazaki, Seismicity in source regions of large interpolate earthquakes around Japan and the characteristic earthquake model, Earth Planets Space, 61, 1041-1052, 2009.

Jordan, T. H., Earthquake predictability, brick by brick, Seismol. Res. Lett., 77(1), 3-6, doi:10.1785/gssrl.77.1.3, 2006.

Kafka, A. L., Statistical analysis of the hypothesis that seismicity delineates areas where future large earthquakes are likely to occur in the Central and Eastern United States, Seismol. Res. Lett., 73, 990-1001, 2002.

Kagan, Y. Y. and D. Jackson, Probabilistic forecasting of earthquakes, Geophys. J. Int., 143(2), 438-453, doi:10.1046/j.1365-246X.2000. 01267.x, 2000.

Keilis-Borok, V. I., The lithosphere of the Earth as a nonlinear system with implications for earthquake prediction, Rev. Geophys., 28(1), 1934, 1990.

Keilis-Borok, V. I. and V. G. Kossobokov, Premonitory activation of earthquake flow: algorithm M8, Phys. Earth Planet. Inter., 61(1-2), 73-83, doi:10.1016/0031-9201(90)90096-G, 1990.

Keilis-Borok, V. and I. M. Rotwain, Diagnosis of time of increased probability of strong earthquakes in different regions of the world, Phys. Earth Planet. Inter., 61(1-2), 57-72, doi:10.1016/0031-9201(90)90095F, 1990.

Keilis-Borok, V. I. and A. A. Soloviev, eds., Nonlinear Dynamics of the Lithosphere and Earthquake Prediction, Springer-Verlag, New York, $341 \mathrm{pp}, 2003$.

Kossobokov, V., Earthquake prediction: basics, achievements, perspectives, Acta Geod. Geoph. Hung., 39(2/3), 205-221, 2004.

Marsan, D. and O. Lengline, Extending earthquakes' reach through cascading, Science, 319, 1076-1079, doi:10.1126/science.1148783, 2008.

Mason, I. B., Binary events, in Forecast Verification, edited by Jolliffe, I. T. and D. B. Stephenson, pp. 37-76, Wiley, Hoboken, 2003.

Molchan, G. M., Strategies in strong earthquake prediction, Phys. Earth Planet. Inter., 61(1-2), 84-98, doi:10.1016/0031-9201(90)90097-H, 1990.

Nanjo, K. Z., J. R. Holliday, C.-C. Chen, J. B. Rundle, and D. L. Turcotte, Application of a modified pattern informatics method to forecasting the locations of future large earthquakes in the central Japan, Tectonophysics, 424, 351-366, doi:10.1016/j.tecto.2006.03.043, 2006a.

Nanjo, K. Z., J. R. Holliday, C.-C. Chen, J. B. Rundle, and D. L. Turcotte, Forecasting locations of future large earthquakes, using Pattern Informatics: A review, Proc. Inst. Stat. Math., 54(2), 281-297, 2006 b.

Nanjo, K. Z., J. B. Rundle, J. R. Holliday, and D. L. Turcotte, Pattern informatics and its application for optimal forecasting of large earthquakes in Japan, Pure Appl. Geophys., 163(11-12), 2417-2432, doi:10.1007/s00024-006-0130-2, 2006c.

Nanjo, K. Z., H. Tsuruoka, N. Hirata, and T. H. Jordan, Overview of the first earthquake forecast testing experiment in Japan, Earth Planets Space, 63, this issue, 159-169, doi:10.5047/eps.2010.10.003, 2011.

Ogata, Y., Space-time point-process models for earthquake occurrences, Ann. Inst. Statist. Math., 50, 379-402, 1998.

Ogata, Y., Significant improvements of the space-time ETAS model for forecasting of accurate baseline seismicity, Earth Planets Space, 63, this issue, 217-229, doi:10.5047/eps.2010.09.001, 2011.

Reasenberg, P., Second-order moment of central California seismicity, 1969-1982, J. Geophys. Res., 90(B7), 5479-5495, doi:10.1029/ JB090iB07p05479, 1985.

Rhoades, D. A. and F. F. Evison, Long-range earthquake forecasting with every earthquake a precursor according to scale, Pure Appl. Geophys., 161(1), 47-72, doi:10.1007/s00024-003-2434-9, 2004.

Rundle, J. B., K. F. Tiampo, W. Klein, and J. S. S. Martins, Selforganization in leaky threshold systems: the influence of nearmean field dynamics and its implications for earthquakes, neurobiology, and forecasting, Proc. Natl. Acad. Sci. U.S.A., 99, 2514-2521, doi:10.1073/pnas.012581899, 2002.

Rundle, J. B., D. L. Turcotte, R. Shcherbakov, W. Klein, and C. Sammis, Statistical physics approach to understanding the multiscale dynamics of earthquake fault systems, Rev. Geophys., 41(4), 1019, doi:10.1029/2003RG000135, 2003.

Schorlemmer, D., M. Gerstenberger, S. Wiemer, and D. D. Jackson, Earthquake likelihood model testing, Seismol. Res. Lett., 78(1), 17-29, doi:10.1785/gssrl.78.1.17, 2007.

Shibutani, T., Y. Iio, S. Matsumoto, H. Katao, T. Matsushima, S. Ohmi, F. Takeuchi, K. Uehira, K. Nishigami, B. Enescu, I. Hirose, Y. Kano, 
Y. Kohno, M. Korenaga, Y. Mamada, M. Miyazawa, K. Tatsumi, T. Ueno, H. Wada, and Y. Yukutake, Aftershock distribution of the 2004 Mid Niigata Prefecture Earthquake derived from a combined analysis of temporary online observations and permanent observations, Earth Planets Space, 57(6), 545-549, 2005.

Stein, R. S., G. C. P. King, and J. Lin, Change in failure stress on the southern San Andreas fault system caused by the 1992 magnitude=7.4 Landers earthquake, Science, 258, 1328-1332, doi:10.1126/science.258.5086.1328, 1992.

Tiampo, K. F., J. B. Rundle, S. McGinnis, S. J. Gross, and W. Klein, Mean field threshold systems and phase dynamics: an application to earthquake fault systems, Europhys. Lett., 60(3), 481-487, doi:10.1209/epl/i2002-00289-y, 2002.

Turcotte, D. L., Earthquake prediction, Ann. Rev. Earth Planet. Sci., 19, 263-281, 1991.

Turcotte, D. L., Fractals and Chaos in Geology and Geophysics, 398 pp, Cambridge Univ. Press, New York, 1997.

Wessel, P. and W. H. F. Smith, Free software helps map and display data, Eos Trans. AGU, 72(41), 441, doi:10.1029/90EO00319, 1991.

Wiemer, S., A software package to analyze seismicity: ZMAP, Seismol. Res. Lett., 72, 373-382, 2001.

Wiemer, S. and D. Schorlemmer, ALM: An asperity-based likelihood model for California, Seismol. Res. Lett., 78(1), 134-140, doi:10. 1785/gssrl.78.1.134, 2007.

Wiemer, S. and M. Wyss, Mapping spatial variability of the frequency- magnitude distribution of earthquakes, Adv. Geophys., 45, 259-302, doi:10.1016/S0065-2687(02)80007-3, 2002.

Woessner, J. and S. Wiemer, Assessing the quality of earthquake catalogs: Estimating the magnitude of completeness and its uncertainties, Bull. Seismol. Soc. Am., 95(2), 684-698, doi:10.1785/0120040007, 2005.

Wyss, M., Nomination of precursory seismic quiescence as a significant precursor, Pure Appl. Geophys., 149(1), 79-113, doi:10.1007/ BF00945162, 1997.

Wyss, M. and A. H. Martirosyan, Seismic quiescence before the M 7 1988 Spitak earthquake, Armenia, Geophys. J. Int., 134(2), 329-340, doi:10.1046/j.1365-246x.1998.00543.x, 1998.

Wyss, M. and S. Wiemer, Change in the probability for earthquakes in southern California due to the Landers magnitude 7.3 earthquake, Science, 290, 1334-1338, doi:10.1126/science.290.5495.1334, 2000.

Yamashina, K. and K. Z. Nanjo, An improved relative intensity model for earthquake forecast in Japan, Earth Planets Space, 2011 (in press).

Zechar, J. D. and T. H. Jordan, Testing alarm-based earthquake predictions, Geophys. J. Int., 172, 715-724, doi:10.1111/j.1365-246X.2007. 03676.x, 2008.

Zhuang, J., Y. Ogata, and D. Vere-Jones, Stochastic declustering of space-time earthquake occurrences, J. Am. Stat. Ass., 97, 369-380, doi:10.1198/016214502760046925, 2002.

K. Z. Nanjo (e-mail: nanjo@eri.u-tokyo.ac.jp) 